\title{
Causes of Gross Hematuria in Patient at a Tertiary Care Hospital
}

\author{
Nizam ud Din 1, Ahmed Sajjad 2, Saadat Hassan Hashmi ${ }^{3}$, Masroor Hussain Malik ${ }^{4}$, Zein-El-Amir 5 , \\ Zeeshan Qadeer ${ }^{6}$ \\ ${ }^{1}$ Assistant Professor (Urology) Department of Urology, Saidu Group of teaching hospital Swat \\ ${ }^{2,3}$ Consultant urologist, Department of Urology, Benazir Bhutto Hospital Rawalpindi \\ 4,5 Assistant Professor urology, Department of urology, Rawalpindi Medical University \\ ${ }^{6}$ Senior Registrar, Department of Urology, Benazir Bhutto Hospital Rawalpindi
}

\begin{abstract}
Objective: To determine the causes of hematuria in patients coming to a tertiary care hospital.

Patients and Methods: This cross-sectional study was carried out at Pakistan Institute of Medical Sciences (PIMS), Islamabad, Pakistan. Data was collected over a period of six months (June 2016 to December 2016). Data of all the adult male and female patients presenting with complaint of gross hematuria during the period were gathered and analyzed for etiological profile.

Results: In the study the most common cause was urological malignancy, which was present in $29(58 \%)$ of patients. This includes all the urological cancers. Among other causes, $11(22 \%)$ patients had urolithiasis while $5(10 \%)$ patients had gross hematuria due to trauma to renal tract. $3(6 \%)$ males had hematuria due to enlarged vascular prostate and only $2(4 \%)$ females had gross hematuria due to urinary tract infection.

Conclusion: Urological malignancy was the most common cause of gross hematuria, which is associated with male gender, older age and history of smoking. Other causes were urolithiasis, trauma, BPH and UTI. We recommend screening for malignant disease of all the patients presenting to the departments of urology with the complaint of gross hematuria.

Key words: Hematuria, Urolithiasis, Urological Malignancy

Author's Contribution

${ }^{1-2}$ Conception, synthesis, planning of research and manuscript writing Interpretation and discussion

${ }^{3-6}$ Data analysis, interpretation and manuscript writing, Active participation in data collection.

Cite this article. Nizam-ud-Din, Sajjad A, Hashmi SH, Malik MH, Zein-el-Amir, Qadeer Z. Cause of Gross Hematuria in Patient at a Tertiary Care Hospital. JIMDC.2018; 7(4):269-273

\section{Address of Correspondence}

Ahmed Sajjad

Email: drahmedsajjad@hotmail.com

Article info.

Received: April 16, 2018

Accepted: July 10, 2018

\section{Introduction}

Hematuria is defined as the presence of more than five red blood cells/HPF in three consecutive urine samples, taken at least one-week apart. ${ }^{1}$ Hematuria that is not explained by an obvious underlying condition is commonly seen in urological practice. In many such patients, particularly young adult patients, the hematuria is transient and with no consequence. On the other hand, there is an appreciable risk of malignancy particularly in

older patients (eg, over age 35 years) with hematuria, even if transient. ${ }^{2}$ Presentation of gross hematuria can be overtly bloody, tea colored, smoky or microscopic. ${ }^{3}$ Urinary tract malignancies (bladder, ureter and kidney) are distinct clinical entities. Hematuria is a common presentation in all these diseases. ${ }^{2}$ Condition can be asymptomatic or symptomatic, transient or persistent; it may or may not be associated with proteinuria or other
\end{abstract}




\begin{tabular}{|c|c|c|c|}
\hline \multicolumn{2}{|c|}{ Baseline Characteristics } & Number (n) & Percentage (\%) \\
\hline \multirow{4}{*}{$\begin{array}{l}\text { Age (mean } 44.8 \pm 17.2 \text { years; range:17-78 } \\
\text { years) }\end{array}$} & Upto 30 years & 15 & 30 \\
\hline & $31-50$ years & 14 & 28 \\
\hline & $>50$ years & 21 & 42 \\
\hline & Total & 50 & 100 \\
\hline \multirow[t]{4}{*}{ Gender } & Males & 40 & 80 \\
\hline & Females & 10 & 20 \\
\hline & Total & 50 & 100 \\
\hline & $\mathrm{M}: \mathrm{F}$ & \multicolumn{2}{|r|}{ 4:1 } \\
\hline \multirow{3}{*}{ H/o smoking } & Smokers & 24 & 48 \\
\hline & Non-smokers & 26 & 52 \\
\hline & Total & 50 & 100 \\
\hline \multirow[t]{7}{*}{ Co-morbids } & No comorbid & 31 & 62 \\
\hline & Hypertension & 7 & 14 \\
\hline & Diabetes & 5 & 10 \\
\hline & Hypertension+ diebetes & 4 & 8 \\
\hline & Cva & 2 & 4 \\
\hline & Asthma & 1 & 2 \\
\hline & Total & 50 & 100 \\
\hline \multirow{4}{*}{$\begin{array}{l}\text { Duration of hematuria (mean } 33.1 \pm 35.3 \text { days; } \\
\text { range:3-120 days) }\end{array}$} & Upto 2weeks & 19 & 38 \\
\hline & 2-4 weeks & 13 & 26 \\
\hline & $>4$ weeks & 18 & 36 \\
\hline & Total & 50 & 100 \\
\hline
\end{tabular}

abnormalities..$^{2-5}$ Evaluation of the hematuria involves a detailed history, physical evaluation and imaging studies. ${ }^{6}$ Presence of the clots in the urine is suggestive of extraglomerular cause. ${ }^{5}$ Fever, abdominal pain and dysuria is associated with UTI. Recent abdominal injury may point towards hydronephrosis. ${ }^{3}$ Glomerular disease presentation is early morning periorbital puffiness, weight gain, dark colored urine, edema and hypertension. Hematuria with glomerular causes is painless. ${ }^{7}$ A recent history of skin or throat infection may suggest post infection glomerulonephritis.$^{8}$ Among adult's, joint pains, skin rash and prolonged fever are suggestive of collagen vascular diseases. In case of anemia, hematuria cannot be the sole cause, in such cases other factors must be counted on. In Henoch-Schonlein purpura and systemic lupus erythematosus, arthritis and rashes are a common presentation. Information regarding exercises, menstruation, and bladder catheterization, recent intake of drugs or toxins or passage of a calculus may be helpful in differential diagnosis. Further family history of the Alports syndrome, CVD, polycystic disease and urolithiasis is critical for differential diagnosis. ${ }^{9}$ Other denominators in the diagnosis of hematuria are age, sex and race. Hematuria is a sign and not a disease, though it may be an early presentation of urinary tract cancers, so clinicians should focus on the root cause identification and eradication. ${ }^{10}$

Currently, there is very limited data on etiological profile of hematuria in Pakistani Population. Present study was designed to gather data from urology department of tertiary care hospital. As there is an appreciable risk of malignancy particularly in older patients, the study will 
help in devising departmental guidelines in order to identify those high risk patients at an earlier stage. Our main objective was to determine the causes of hematuria in adult Pakistani population.

\section{Patients and Methods}

This cross-sectional study was carried out at Pakistan Institute of Medical Sciences (PIMS), Islamabad. Data was collected over a period of six months (June 2016 to December 2016). Study design was approved by the hospital ethical committee and informed consent was obtained from all study participants. Data of all the adult male and female patients coming to urology outpatient and emergency department of PIMS with the complaint of gross hematuria was gathered and analyzed for etiological profile. The patients underwent a comprehensive protocol of investigations. These include complete blood count, ESR, complete urine examination. Renal function was assessed with serum creatinine, blood urea, and serum electrolytes including potassium, sodium, calcium and phosphate. Results of urine cytology, urine culture, imaging studies and cystoscopy was also evaluated. Statistical software SPSS 22 was used for data analysis.

\section{Results}

In this study we included 50 patients with gross hematuria, $40(80 \%)$ patients were male and $10(20 \%)$ were female, with a male to female ratio of $4: 1$. Age ranged from 17 years to 78 years with median 41.5 years. In the total sample size of 50 , fifteen $(30 \%)$ patients were less than 30 years while twenty-one (42\%) were more than 50 years of age (Table 1). In the study most common cause was urological malignancy which was present in 29 $(58 \%)$ of patients. This includes all the urological cancers.

\section{Table 2: Causes of hematuria in study population}

\begin{tabular}{|l|c|}
\hline \multicolumn{1}{|c|}{ Causes } & $\mathbf{n ( \% )}$ \\
\hline Urological malignancy & $29(58 \%)$ \\
\hline Urolithiasis & $11(22 \%)$ \\
\hline Uro-trauma & $5(10 \%)$ \\
\hline BPH & $3(6 \%)$ \\
\hline Urinary tract infection & $2(4 \%)$ \\
\hline
\end{tabular}

\begin{tabular}{|l|c|c|}
\hline \multicolumn{3}{|c|}{ Table 3: Gender based stratification } \\
\hline \multicolumn{1}{|c|}{ Causes } & $\begin{array}{c}\text { Male }(\mathbf{n}=40) \\
\mathbf{n}(\%)\end{array}$ & $\begin{array}{c}\text { Female }(\mathbf{n}=10) \\
\mathbf{n}(\%)\end{array}$ \\
\hline $\begin{array}{l}\text { Urological } \\
\text { malignancy }\end{array}$ & $26(89.7)$ & $3(10.34)$ \\
\hline Urolithiasis & $4(80)$ & $1(20)$ \\
\hline Uro-trauma & $7(63.6)$ & $4(36.4)$ \\
\hline $\begin{array}{l}\text { Urinary tract } \\
\text { infection }\end{array}$ & $0(0)$ & $2(100)$ \\
\hline BPH & 3 & - \\
\hline
\end{tabular}

In total, $11(22 \%)$ patients had urolithiasis while $5(10 \%)$ patients had gross hematuria due to trauma to renal tract, $3(6 \%)$ males had hematuria due to enlarged vascular prostate and only $2(4 \%)$ females had gross hematuria due to urinary tract infection (table 2). Urological malignancy was significantly associated with history of smoking; it was observed that $62.1 \%$ of the participants with urological malignancy were smoker while $37.9 \%$ were nonsmoker. Gender based stratification showed patients with urological malignancy were mostly males $(n=26 / 29,89.7 \%)$. Patients with uro-trauma and urolithiasis were also mostly males and patients with UTI were all females (Table 3). Age based stratification showed that most patients with urological malignancy were $>50$ years of age $(n=17 / 29,58.6 \%)$ and all patients with $\mathrm{BPH}$ (Benign prostatic hyperplasia) were also $>50$ years of age, most of the patients with uro-trauma were < 30 years of age $(n=4 / 5,80 \%)$ and all patients with UTI were $<30$ years of age (Table 4 ).

\section{Discussion}

In our study the most common cause was urological malignancy which was present in $29(58 \%)$ of patients. This included all urological cancers. The urological malignancy remains the most common cause of gross hematuria in adults. Patel JV in a similar study reported that the most common differential diagnosis for both microscopic and gross hematuria in adults includes infection, malignancy, and urolithiasis. ${ }^{11}$ Our study results reveal similar information. In another study on patients with asymptomatic microscopic hematuria, Yamamoto $\mathrm{M}$, et al reported that of 236 patients over the age of 40 , 


\begin{tabular}{|l|c|c|c|c|}
\hline \multicolumn{5}{|c|}{ Table 4: Age based stratification } \\
\hline Causes & $\begin{array}{c}\text { Up to 30 } \\
\text { years } \\
(\%)\end{array}$ & $\begin{array}{c}31-50 \\
\text { years } \\
(\%)\end{array}$ & $\begin{array}{c}>50 \\
\text { years } \\
(\%)\end{array}$ & $\begin{array}{c}\text { Total } \\
\text { (n) }\end{array}$ \\
\hline $\begin{array}{l}\text { Urological } \\
\text { malignancy }\end{array}$ & $1(3.4)$ & $\begin{array}{c}11 \\
(37.9)\end{array}$ & $17(58.6)$ & 29 \\
\hline Urolithiasis & $8(72.2)$ & $3(27.3)$ & 0 & 11 \\
\hline Uro-trauma & $4(80)$ & 0 & $1(20)$ & 5 \\
\hline BPH & 0 & 0 & $3(100)$ & 3 \\
\hline $\begin{array}{l}\text { Urinary tract } \\
\text { infection }\end{array}$ & $2(100)$ & 0 & 0 & 2 \\
\hline
\end{tabular}

$6.8 \%$ were found to have a genitourinary cancer, while $27.5 \%$ had other significant urologic disease. However, $52.1 \%$ of the patients had unknown etiology of microscopic hematuria and $13.6 \%$ had insignificant urologic lesions. Of the 72 patients under the age of $40 \mathrm{a}$ positive diagnosis was made in 16 patients $(22.2 \%){ }^{12}$ The apparent differences in the rates of urological malignancy in their study $(6.8 \%)$ and present study (58\%) may be attributed to different patient inclusion criteria. They analyzed patients with asymptomatic microscopic hematuria while we analyzed patients with gross hematuria. Considering high level of malignancy rate in our study, we can safely assume, it may be the result of late presentation of the patients at our facility, where most of the time, the cases are referred from remote areas, when symptoms are aggressive and failure of standard symptomatic treatments at GP clinics. There can be a role of socio-economic situations in the country and current practicing trends can be a major factor, thus we recommend that in future these factors should be considered along with standard parameters so that a clearer and multidimensional picture can be assessed.

In another local study conducted in department of urology, Mayo Hospital, Lahore it was concluded that 54\% patients with gross hematuria had malignancy. ${ }^{13} \mathrm{~A}$ study conducted in Srilanka by Goonewardena SA et al showed that bladder cancer (Urological malignancy) remains the commonest cause of gross hematuria in patients above 40 years of age. ${ }^{14}$ Our results are quite comparable with these national and international studies as we have also concluded that the urological malignancy remains the common cause of the gross hematuria in our setup (58\%).
In the study of society statistics of hematuria done in 2002-2003, in hospital episode statistic department of health, England 2002-2003, 65\% men and 35\% women consulted for management of gross hematuria. In hospital episode statistic, department of health England 20022003, hematuria occurred in 15-59 years old group in about $44 \%$ of the patients and in the same study $24 \%$ of the people were above 75 years of age. ${ }^{15}$

Among total $29(58 \%)$ patients having urological malignancy, $26(89.7 \%)$ were males and only $3(10.3 \%)$ were females. In a study conducted in wine wells hospitals and Medical School and University of Dundee, Scotland, UK it was concluded that $25 \%$ of patients presenting with frank hematuria had malignancy and in the same study, it was also concluded that males were more likely than females to have malignancy. ${ }^{16}$ Studies conducted at Mc Gill University, Canada and in USA, showed that primary health care providers are over using routine urine analysis in the absence of clear indications. While at the same time referral ratio for specialist investigation is lower. These studies concluded that cases of hematuria shall be looked carefully and possibility of the serious conditions like urological malignancy should not be ignored. ${ }^{17,18}$

Contrary to above mentioned studies, a large scale study showed that microscopic hematuria among patients of age $<40$ can be first assessed by nephrologist due to low risk of malignancy. ${ }^{19} \mathrm{~A}$ retrospective study concluded that patient above age 40 and $>25$ RBC's/HPF are at greater risk of urological malignancy. ${ }^{19}$ The cigarette smoking has got a definite relationship with urinary tract malignancies. In our studies, $29(58 \%)$ of the patients and urological malignancy among them 18 (62.1\%) patients were smokers. Smoking is the most common and important cause of urological malignancy. The study conducted by Amlung CL. ${ }^{20}$ It was proven that cigarette smoking remains the most important cause of bladder cancer. In another study, the cigarette smoking was found as single most important cause of urinary bladder.

Our study results showed that the second common cause was urolithiasis, which was found in eleven (22\%) patients. Similar findings were reported by Irfan et al13 and Goonewardena et $\mathrm{al}^{14}$. Our study results show that the third common cause was urological trauma found in $4 / 5(80 \%)$ of males and $1 / 5(20 \%)$ of females. The trauma 
was common in younger age group. Similar findings were reported by Tarik $\mathrm{K}{ }^{21}$ that gross hematuria is present in all patients having renal trauma. Shabir $M{ }^{22}$ reported that renal trauma was more common in 21-40 years of age and among males $(78 \%)$, which is similar to our study results.

\section{Conclusion}

Urological malignancy is the most common cause of gross hematuria, which is associated with male gender, older age and history of smoking. Other causes include urolothiasis, trauma, BPH and UTI.

\section{References}

1. Higashihara E, Nishiyama T, Horie S.et al. Hematuria: definition and screening test methods. Int $\mathrm{J}$ Urol. 2008;15(4):281-4

2. Nielsen $M$, Qaseem A. Hematuria as a Marker of Occult Urinary Tract Cancer: Advice for High-Value Care from the American College of Physicians. Ann Intern Med. 2016; 164(7):488-97

3. Brannigan RE. Urology. Med Clin North Am. 2018;102(2):17-9

4. Tu WH, Shortliffe LD. Evaluation of asymptomatic, a traumatic hematuria in children and adults. Nat Rev Urol. 2010; 7(4):189-94

5. Crompton $\mathrm{CH}$, Ward PB, Hewitt IK. The use of urinary red cell morphology to determine the source of hematuria in children. ClinNephrol. 1993;39(1):449

6. Lisanti CJ, Toffoli TJ, Stringer M. CT evaluation of the upper urinary tract in adults younger than 50 years with asymptomatic microscopic hematuria: is IV contrast enhancement needed? AJR Am J Roentgenol 2014; 203(3):615

7. Kincaid-Smith $P$, Fairley K. The investigation of hematuria. Semin Nephrol. 2005;25(3):127-35

8. Cybulsky AV, Walsh M, Knoll G, Hladunewich M, Bargman J, Reich $\mathrm{H}$, et al. Canadian Society of Nephrology Commentary on the 2012 KDIGO clinical practice guideline for glomerulonephritis: management of glomerulonephritis in adults. Am J Kidney Dis. 2014;63(3):363-77

9. Kashtan CE. Familial hematuria. PediatrNephrol. 2009;24(10):1951-8
10. Nielsen M, Qaseem A. High Value Care Task Force of the American College of Physicians. Ann Intern Med. 2016;164(7):488-97

11. Patel JV, Chambers CV, Gomella LG. Hematuria: etiology and evaluation for the primary care physician. Can J Urol. 2008;15(1):54-61

12. Yamamoto $M$, Hibi $H$, Miyake $K$. Etiology of asymptomatic microscopic hematuria in adults. Kiyo K. 1993;39(5):413-7

13. Ahmed I, Sheikh NA. Evaluation of patients with hematuria in district general hospital. Ann King Edward Med Coll. 1999;5(3,4):238-9

14. Goonewardena SA, AbeygunasekeraAM. Haematuria as the presenting symptom: experience from a tertiary referral centre in Sri Lanka. The Ceylon medical journal. 1998;43(3):156-8

15. Hospital Episode Statistics, Department of Health, England, 2002-03. Canadian urological association journal. 2014;8:E481-5

16. Ali S, Byrne D, Goodman M. Hematuria investigation based on a standard protocol: Emphasis on the diagnosis on urological malignancy. JR Coll Surgery Edin. 2002; 47(1):771-2

17. Yafi FA, Aprikian AG, Tanguay S, Kassouf W. Patients with microscopic and gross hematuria: practice and referral patterns among primary care physicians in a universal health care system. Canadian Urological Association Journal. 2011;5(2):97-101

18. Nieder AM, Lotan Y, Nuss GR, Langston JP, Vyas S, Manoharan M, Soloway MS. Are patients with hematuria appropriately referred to Urology? A multiinstitutional questionnaire based survey. In Urologic Oncology: Seminars and Original Investigations. 2010;28(5):500-3

19. Kotb AF, Attia D. High-grade microscopic hematuria in adult men can predict urothelial malignancy. Canadian Urological Association Journal. 2014;8(78): E481-5

20. Amlung $\mathrm{CL}$. Diagnosis and management of superficial bladder cancer. Curr Probl Cancer. 2001; 25(4):21928

21. Tarik K, Fossi J, Sadiq A. Complications of renal trauma. . Ann Urol (Paris). 2000;34:249-53

22. Sabir M, Babar AM. Epidemiology and management of renal injuries. Pakistan J Surgery. 2002;18(2):1720. 